\title{
Elongated theropod tracks from the Cretaceous Apenninic Carbonate Platform of southern Latium (central Italy)
}

\author{
Paolo Citton, Umberto Nicosia, lacopo Nicolosi, \\ Roberto Carluccio, and Marco Romano
}

\begin{abstract}
New dinosaur footprints were recently discovered in southern Latium (Italy). The tracks all appear slightly differently preserved and are characterized by elongated metatarsal impressions, recording the complex locomotor behaviour of a medium-sized theropod. The spatial distribution and the features of the footprints indicate that the trackmaker adopted a "crouched" position as part of an activity as well as a resting phase suggested by sub-parallel, calcigrade tracks. These new data once again highlight the great potential of ichnological evidence in the study of the biology and behaviour of extinct tetrapods.
\end{abstract}

Paolo Citton. Dipartimento di Scienze della Terra, "Sapienza" Università di Roma, Piazzale Aldo Moro 5, 00185, Rome, Italy. paolo.citton@uniroma1.it

Umberto Nicosia. Dipartimento di Scienze della Terra, "Sapienza" Università di Roma, Piazzale Aldo Moro 5, 00185, Rome, Italy. umberto.nicosia@uniroma1.it lacopo Nicolosi. Istituto Nazionale di Geofisica e Vulcanologia, Via di Vigna Murata 605, 00143 Roma, Italy. iacopo.nicolosi@ingv.it

Roberto Carluccio. Istituto Nazionale di Geofisica e Vulcanologia, Via di Vigna Murata 605, 00143 Roma, Italy. roberto.carluccio@ingv.it

Marco Romano. Dipartimento di Scienze della Terra, "Sapienza" Università di Roma, Piazzale Aldo Moro 5, 00185, Rome, Italy; Sam Noble Museum, 2401 Chautauqua Ave., Norman, Oklahoma 73072, USA. marco.romano@uniroma1.it (corresponding author)

Keywords: theropod footprints; metatarsal traces; crouching posture; Italy; photogrammetry

Submission: 6 June 2015. Acceptance: 16 September 2015

\section{INTRODUCTION}

Fossil footprints and trackways constitute a remarkable reservoir of data about gait, posture, limb, and foot kinematics, ethology, and metabolism in early terrestrial vertebrates and dinosaurs (e.g., Currie and Sarjeant, 1979; Baird, 1980; Carpenter, 1992; Farlow, 1992; Barnes and Lockley,
1994; Avanzini, 1998; Gatesy et al., 1999; Blob, 2001; Milàn et al., 2006). In some fortunate cases, ichnological material includes traces, which may record more information such as the skin texture, the resting of the tail on the ground, the ischial callosity, the metatarsal area, or the traces of excreta (e.g., Currie et al., 1991; Avanzini, 2000; Fernandes et al., 2004; Platt and Hasiotis, 2004;

Citton, Paolo, Nicosia, Umberto, Nicolosi, lacopo, Carluccio, Roberto, and Romano, Marco. 2015. Elongated theropod tracks from the Cretaceous Apenninic Carbonate Platform of southern Latium (central Italy). Palaeontologia Electronica 18.3.49A: 1-12 palaeo-electronica.org/content/2015/1340-elongated-theropod-tracks 


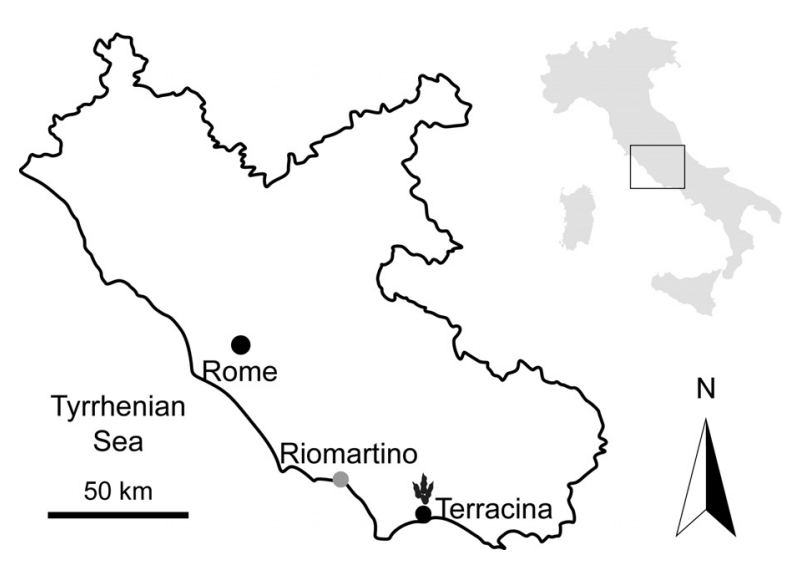

FIGURE 1. Map of provenance (black footprint) and present location of the track-bearing block (Lido di Porto Canale-Riomartino, grey spot).

Souto and Fernandes, 2015). All such features greatly expand the potential information on extinct tetrapod palaeobiology. Tetrapod footprints can also be analyzed within a framework of "reciprocal illumination" (sensu Carrano and Wilson, 2001; see also (Romano et al., 2015), where the integrated and refined study of osteology and the type of impressions may shed light on the biomechanics, functionality, and complex locomotor cycle of a putative trackmaker (see Voigt et al., 2007; Romano and Citton, 2014; Sacchi et al., 2014; Romano et al., 2015.

Dinosaur footprints with metatarsal traces are common in the dinosaurian ichnological record; they are often reported as isolated tracks and, less frequently, as part of a trackway segment. Previously described material has been attributed both to ornithischian and theropod trackmakers (e.g., Kuban, 1989 and reference therein; Lockley et al., 2003; Nicosia et al., 2007; Milán et al., 2008; Gierlinski et al., 2009; Milner et al., 2009; Wilson et al., 2009). Recently, new dinosaur footprints with metatarsal impressions were discovered on an isolated block of the pier of Porto Canale-Riomartino, a few kilometres from the city of Latina (Latium, Central Italy). The track-bearing limestone block was excavated from a quarry close to Terracina (Latium, Central Italy) and carried to Riomartino for the renovation of the dock (Figure 1).

The tracks represent a significant find because they indicate a bipedal trackmaker adopting a lowered posture after which a resting phase and a subsequent step in a crouched or "squatted" position occur. This paper presents a morphological description of the main ichnological features and parameters of the new tracks as well as an interpretation of the complex movements made by the trackmaker and of the dynamics of track's formation.

\section{Geological Setting}

In the recent past, dinosaur footprints have proven pivotal in better understanding the palaeogeography of the central Mediterranean area (Conti et al., 2005; Nicosia et al., 2007; Turco et al., 2007; Sacchi et al., 2009; Zarcone et al., 2010; Citton et al., 2015). In central and southern Italy, the dinosaur track record covers a time span from the Late Jurassic to the Late Cretaceous and is related to shallow water carbonate successions pertaining to two different palaeogeographic domains, the Apenninic Carbonate Platform (i.e., Latium-Abruzzi and Campania platforms) and the Apulian Platform.

Taking into account its original provenance, the new finding belongs to the Ausoni Mountains, which, together with the Lepini and Aurunci mountains, constitute part of the Volsci Range. This range represents the innermost portion of the Apenninic Carbonate Platform (Cosentino et al., 2002; Centamore et al., 2007) bounded to the west by pelagic deposits of the Umbria-Marche-Sabina Basin (Parotto and Praturlon, 1975). The Aurunci and Ausoni mountains constitute the most landward portion of the Latium-Abruzzi Carbonate Platform. In this domain, the typical sedimentary succession consists of Upper Triassic-Upper Cretaceous neritic carbonate sediments of an inner shelf environment (Chiocchini and Mancinelli, 1977; Chiocchini et al., 1984; Accordi et al., 1988). Such sequences are typical of carbonate platform areas in which the carbonate deposition counterbalances accommodation changes and causes fluctuations from shallow subtidal up to supratidal environments (Chiocchini et al., 1994; Centamore et al., 2007). Short emersion events are mainly scattered in the early Aptian-Cenomanian time interval (Accordi et al., 1967; Rossi et al., 2002; Chiocchini et al., 2012).

The track-bearing block measures approximately $210 \mathrm{~cm}$ in width, $226 \mathrm{~cm}$ in length, and 60 $\mathrm{cm}$ in thickness. It is composed of hazel-colored limestone with a prevalent mudstone-wackestone texture. The microfauna is characterized by Cuneolina sliteri, Nezzazata isabellae (Figure 2.12) and Arenobulimina gr. cochleata, subordinate ostracods, abundant shell fragments, and very rare oncoids. A late Aptian-?early Albian age can be assigned to the assemblage on the basis of Cuneolina sliteri Arnaud-Vanneau and Premoli 

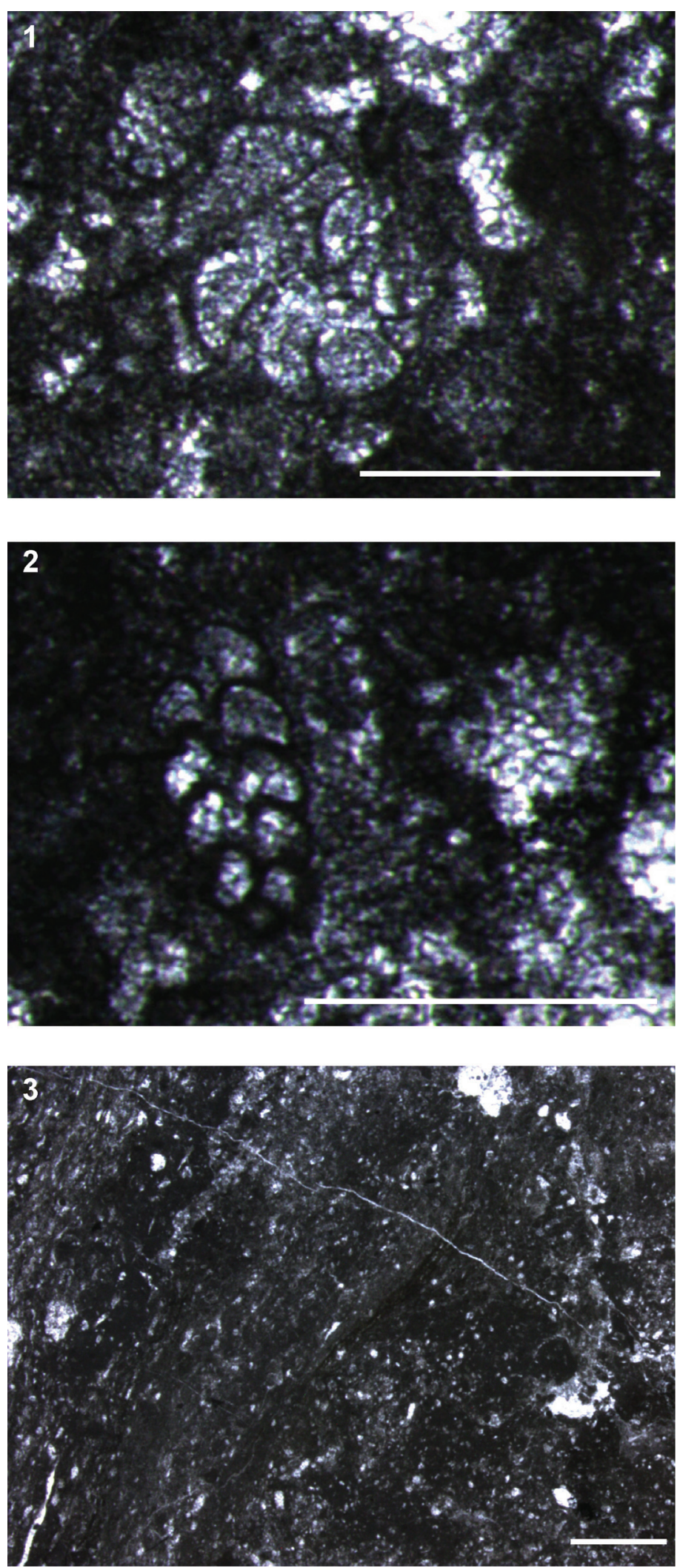

FIGURE 2. Thin sections of the trampled block. 1, Nezzazata isabellae; 2, Cuneolina sliteri; 3, Aligned spathic calcite crystals suggesting emersive condition of the surface during trampling. Scale bar equals $0,5 \mathrm{~mm}(\mathbf{1}$ and $\mathbf{2})$ and 1,5 $\mathrm{mm}(3)$. 
Silva, 1995 (Chiocchini et al., 2012). Unfortunately, a pervasive recrystallization affecting approximately two-thirds of the block's thickness has obliterated the original fabric, making it difficult to make any useful petrographic observations. In thin section, however, aligned spathic calcite crystals characterizing the top of the block strongly suggest emergent conditions during track registration (Figure 2.3).

\section{MATERIAL AND METHODS}

For the measurements and the terminology, the methods of Leonardi (1987) were followed. The main morphometric parameters considered were the stride length, footprint length (FL), footprint width (FW), total digit divarication, interdigital angle, and protrusion of digit III beyond the line that links digits II and IV tips (pIII), which defines the anterior triangle. Metatarsal impression and metatarsal impression length refer to the elongated and narrow portion of the track which terminates before the footprint widens distally. The actual length of the metatarsus is obviously greater, as testified by the position of the possible metatarsal-phalangeal pad of digits III and IV placed just proximal to the hypex between the two digits (see below).

A 3D model of the trampled block was achieved using a high-resolution digital photogrammetry method; this is a technique based on Structure from Motion (SfM) (Ullman, 1979) and Multi View Stereo (MVS) (Seitz et al., 2006) algorithms and takes advantage of modern computational power and high quality photos from low cost digital cameras.

Digital photogrammetry allows for the reconstruction of a full 3D metric model of any object in space starting from a suitable number of photographic images (2D object projection) of a static scene taken from different points of view. In order to achieve suitable results for scientific applications it is important that objects possess locally unique texture and pictures are taken in order to maintain a high "overlay redundancy index" and a small angular separation between images. The former index can be thought of as the average number of pictures in which a set of surveyed surface points are present. This technique produces high-quality dense point clouds with no spatial information that can be used to generate 3D models. Digital photogrammetry generates models comparable to those obtained from LiDAR technology, although the number and overlap of images plays a key role in the robustness of generated models; image redun- dancy can dramatically lower general errors in model processing.

A number of software solutions do exist for digital photogrammetry, designed for both aerial and close-range imagery. A new and widely used software package, Agisoft PhotoScan Pro, (www.agisoft.com) is geared toward semi-automatic processing of images with the end goal of the creation of 3D textured meshes. PhotoScan can handle a wide range of digital images and automatically calculates camera calibrations.

The photogrammetric process used images acquired using a 10.5 Megapixel Canon EOS 400D with $18 \mathrm{~mm}$ focal length. In order to achieve good image overlap, a total of 245 images were used in 3D model construction. In order to correctly scale the calculated model, a metric reference marker was applied on the block surface. A dense cloud mean resolution of $1 \mathrm{~mm}$ was obtained.

\section{ICHNOLOGICAL ANALYSIS}

Variably preserved tracks (concave hyporeliefs) and unclear traces are preserved on the block. They are clearly seen on the eastern side of the block (Figure 3.1-2), as well as on the orthophoto obtained by the image dataset and on the field drawing (Figure 3.3-4; see Appendix 1 for the $3 \mathrm{D}$ interactive model of the track-bearing block). Unfortunately, the sparse detail seen in the traces indicated as A-D in Figure 3.4 make any interpretation of the footprint itself too speculative, so these traces are only briefly discussed later. The spatial distribution and arrangement of these tracks were also analysed, but it has not been possible to define their relationships precisely.

The tridactyl tracks (indicated as F1, F2, and F3 in Figure 3.4) are better preserved even though they are characterized by quite different preservation styles, probably controlled by different substrate conditions during track production. This is clearly indicated by the various qualities of the anatomical details and the associated extramorphologies in the studied tracks.

As can be seen in Figure 3, tracks F1 and F2 are roughly parallel, whereas track $\mathrm{F} 3$ lies directly in front of $F 1 . F 1$ and $F 2$ (FL in F1 is about $38 \mathrm{~cm}$ including the entire metatarsal trace) are faintly impressed with digits very poorly defined. F2 has digits appearing as highly shortened compared with F1 and F3, and the hypices are roughly located at the same level, probably due to a preservational bias (see Petti et al., 2008) controlled by the poor plasticity of the substrate (e.g., greater sediment moisture). Moreover, the expulsion rims 

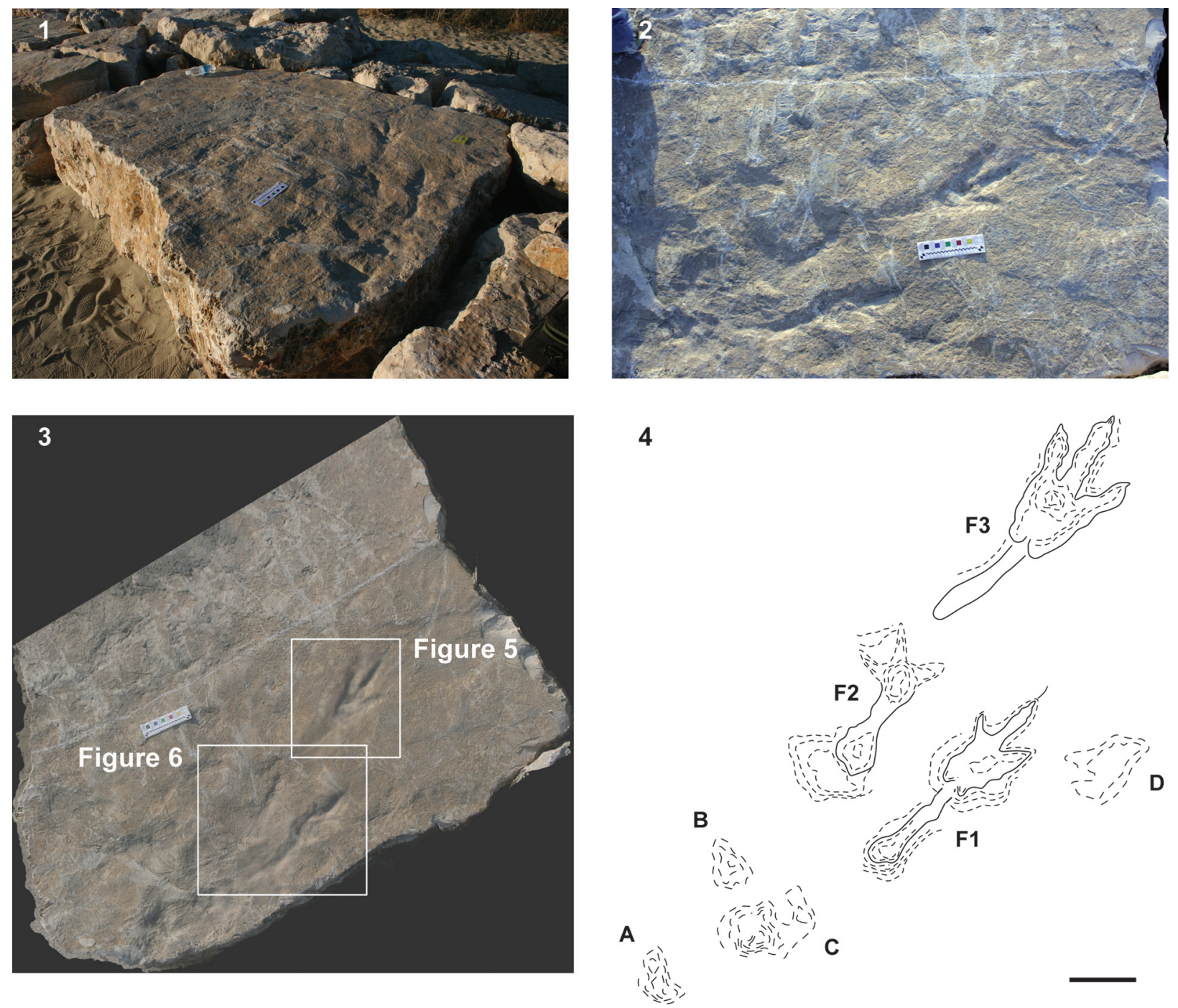

FIGURE 3. 1, The track-bearing block; 2 , Close-up of the studied footprints; 3 , Orthophoto of the trampled block; 4 , Interpretative field drawing (scale bar equals $10 \mathrm{~cm}$ ); F1, F2 and F3 indicate the three theropod tracks discussed in the text; A-D indicate poorly preserved traces, possibly produced by the trackmaker of F1, F2, and F3.

in F1 and F2 are weakly developed and connected to the block surface by a gentle slope. These are different from the rims associated with $\mathrm{F} 3$ which are better developed and possess more vertical walls, suggesting a substrate with a greater cohesion. On the basis of these preservational features, F1 and F2 could be defined as "modified true tracks" (sensu Marty et al., 2009), whereas the F3 could be classified as a "true track" (sensu Lockley, 1991; Marty et al., 2009).

The far better preservation of F3 allows a more accurate assessment of the morphological and morphometrical features of the tracks. This track ( $\mathrm{FL}$ about $40 \mathrm{~cm}$ including the metatarsal trace) is mesaxonic, asymmetric, with a roughly straight digit III showing a pointed claw mark. The protrusion of digit III (pIII) is about $6 \mathrm{~cm}$. The ratio between the digit III projection and the footprint length (excluding the metatarsal impression) is about 0.3 . According to Lockley (2009), track (Fl/w) and anterior triangle length/width (ATI/w) ratios are, respectively, 2.65 and 1.52 . At least two phalangeal pad impressions are clearly identifiable on digits III and IV, whereas only one can be identified on the inner digit (phalangeal counting has been made by assuming an arthral condition of the plantar digital pads - as recently stressed by Cuesta et al., 2015). Digits III and IV are more deeply impressed than digit II; the depth of the impressions progressively decreases toward the digit tips 
highlighted by the photogrammetric models and relative sections (Figures 4, 5). Depths of the impressions are slightly different from those observed in F2, where the more impressed digits are the third and the second. Total digits divarication is about $41^{\circ}$; interdigital angles are $31^{\circ}$ and $10^{\circ}$ (II^III and III^IV, respectively). All of the tracks are characterized by a roughly ovoid area, more deeply impressed with respect to the nearby elements, behind digits III and IV (Figures 4.2, 5, 6, and relative sections). On the whole, these internal structures were attributed to the action of metatarsal-phalangeal fleshy pads III and IV.

Some interpretations regarding similarities and differences in the three footprints can be made using the metatarsal impressions. In F3, the metatarsal trace consists of a roughly straight and homogeneously impressed structure, which tapers proximally up until it disappears, probably as a result of an incomplete contact of the foot when resting on the ground. In contrast, metatarsal traces in F1 and F2 are characterized by a sub-circular morphology proximally (Figures 4.2, 5, 6) (see a similar configuration of this element on specimens SCP III 11 and SCP III 53 figured in Nicosia et al., 2007 and specimen SGDS.18.T1 figured in Milner et al., 2009), which are deemed consistent with the impression of the ankle area. The ankle trace is more deeply impressed compared to the elongated portion of the metatarsal impression, where the depth is constant along the entire length. This evidence reinforces the preservational interpretation stated above and indicates that the trackmaker's feet were placed, one after the other, roughly horizontal on the substrate without sinking into the mud (see Kuban, 1989; Gatesy et al., 1999).

No trace of a hallux is preserved along the footprint's medial sides. In searching for a putative trackmaker for such traces (currently in progress), the lack of a hallux trace is important when considering the position of that digit in the osteological record, because it would likely have touched the ground.

\section{DISCUSSION}

Taking into account the features described above, the tridactyl footprints from Riomartino are best attributed to a medium-sized, non-avian, theropod trackmaker (Lockley et al., 2003). The traces of the metatarsals are, in fact, quite elongated and, therefore, more similar to the osteological structure of theropods rather than with that of ornithopods. The latter, according to Lockley et al.
(2003), would leave shorter metatarsal impressions. This is in accordance with the "morphodynamic rule" with shorter feet and longer legs in ornithopods and longer feet and shorter legs in theropods (Lockley et al., 2003; see also Thulborn, 1990).

The spatial configuration of the tracks, as well as their three-dimensional geometry, allows for a preliminary reconstruction of the movements performed by the trackmaker. It can be hypothesized that the theropod was moving with upright hindlimbs before squatting down in a resting position without necessarily maintaining the limbs perfectly parallel to each other, as suggested by the configuration of tracks $\mathrm{F} 1$ and $\mathrm{F} 2$.

Before describing the complex possible movement of the trackmaker, a brief discussion of the term "crouching" is needed. In the literature, the term "crouching" has been used several times to indicate both true resting tracks, with parallel metatarsals and traces of ischial callosity and hands, and for single tracks with elongated metatarsals, either isolated or in succession in a trackway, so not parallel but representative of a squatting walking (see Lockley et al., 2003; Milan et al., 2008). Alternatively, according to Lockley et al. (2003) the definition of crouching is more restrictive and requires both the impression of the metatarsals and of ischial callosity in the resting phase. In this case, the authors used the term "complete crouching". Lockley et al. (2003) then considered true crouching as a different form of behaviour compared to a continuous walk in a squatting position, possibly linked to a firmer substrate (at least in the known examples) with the dinosaur stopping to rest at least for a certain period of time. Milan et al. (2008) considered crouching or "full crouching" the condition in which parallel metatarsal traces, the ischial callosity and also the manus are impressed. Under this definition, genuine crouching tracks appear to be relatively rare compared to the complete ichnological record of footprints with elongated metatarsal (see Lockley et al., 2003 and Milan et al., 2008).

Taking into account the depth of the impressions, it is possible to infer that before crouching the trackmaker first placed the right foot on the ground and then the left one. Then, the trackmaker crouched down into a resting position, leaving the metatarsal, the ankle and the potential ischial traces on the surface. After a pause, the trackmaker started walking again by maintaining a squatting posture for a single step, and then presumably reverted back to an upright posture after 


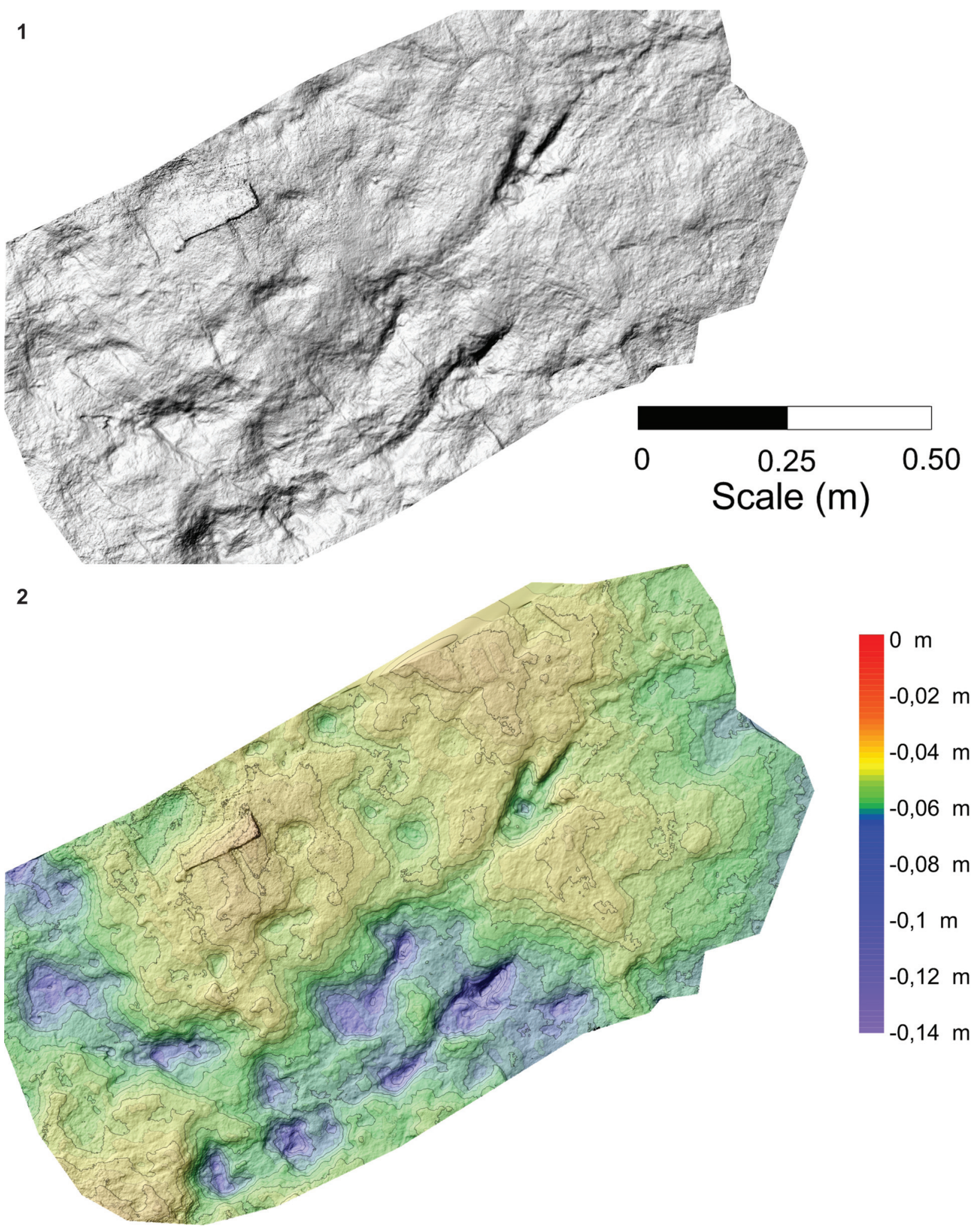

FIGURE 4. 1, Shaded grey 3D photogrammetric model of the track-bearing block; 2, Shaded coloured 3D photogrammetric model. 


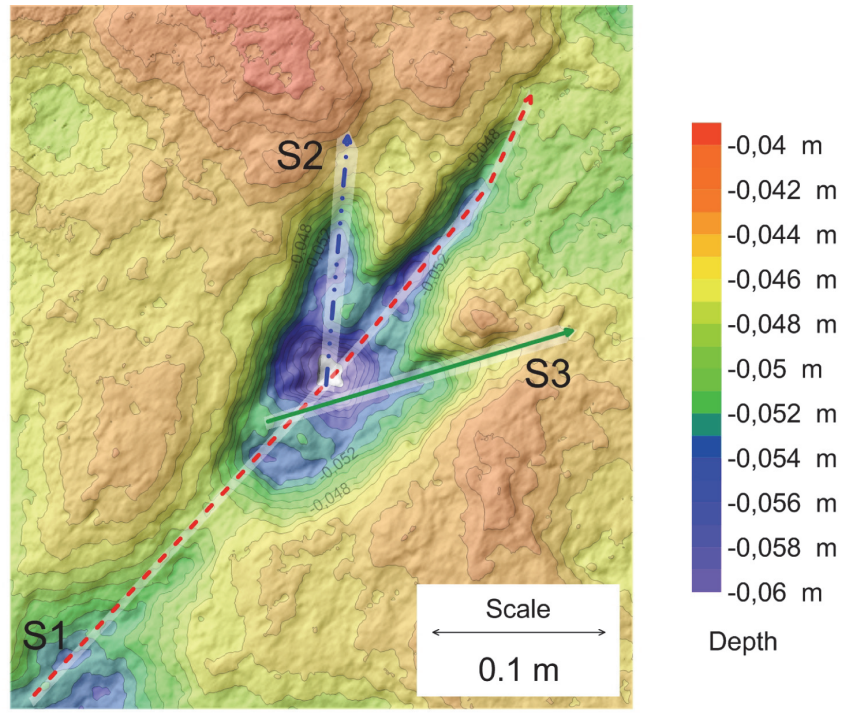

Contour interval $0.001 \mathrm{~m}$

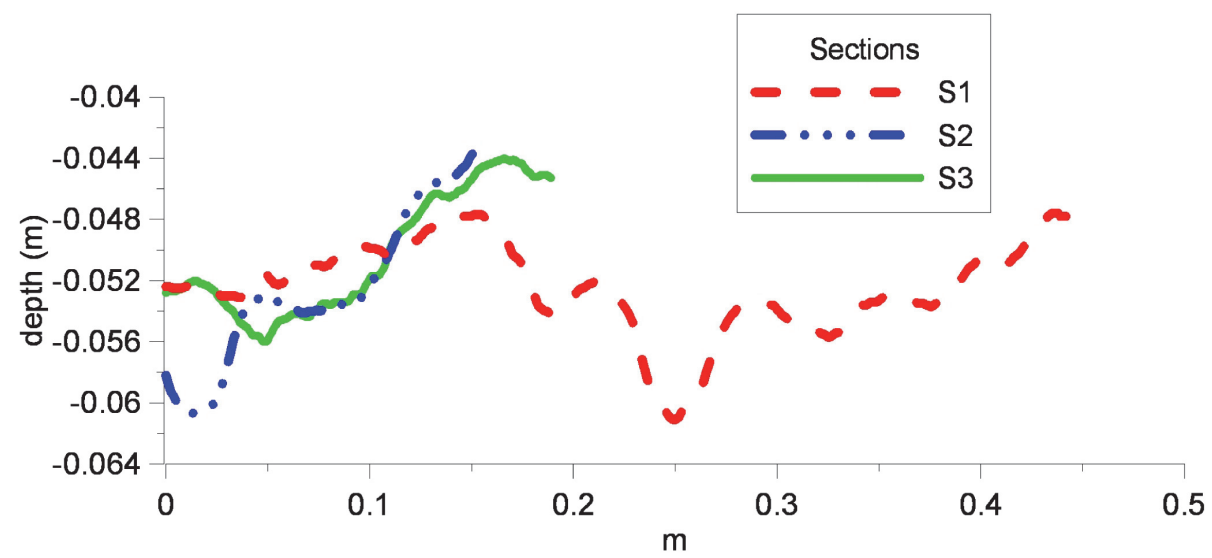

FIGURE 5. Shaded coloured 3D photogrammetric model of footprint F3 and relative sections (S1, S2, S3).

having imprinted F3. In this scenario, the greater depth of the sub-circular portion of the metatarsal impression of F2 could be explained by considering it the result of the interference between two distinct movements. The first occurred after the trackmaker rested the digits on the ground and corresponds to the crouching and stopping phases, the other to the initial phase of locomotion which produced $\mathrm{F} 3$. In this moment, it is possible that the trackmaker performed a complex movement in order to restart walking, exerting pressures both with the right ankle area and with the base of the tail; this accounts for the faintly impressed area surrounding the ischial impression. Considering the block dimensions and the ichnological parameters of the footprints, the lack of other tracks following F3 is considered consistent with a variation in the pace and stride length of the trackmaker due to the final change in posture, rather than to a preservational bias. An attempt to better refine trackmaker attribution as well as a more detailed study of the dynamics of movement and track formation is currently in progress.

\section{CONCLUSIONS}

The newly described dinosaur tracks were produced by a medium-sized, theropod trackmaker with an elongated metatarsus and lacking a hallux. The trackmaker changed its posture from upright to crouched and then stopped, resting on ground before starting to walk again with the same squatting stance during active locomotion. The spatial and three-dimensional configuration of the tracks 

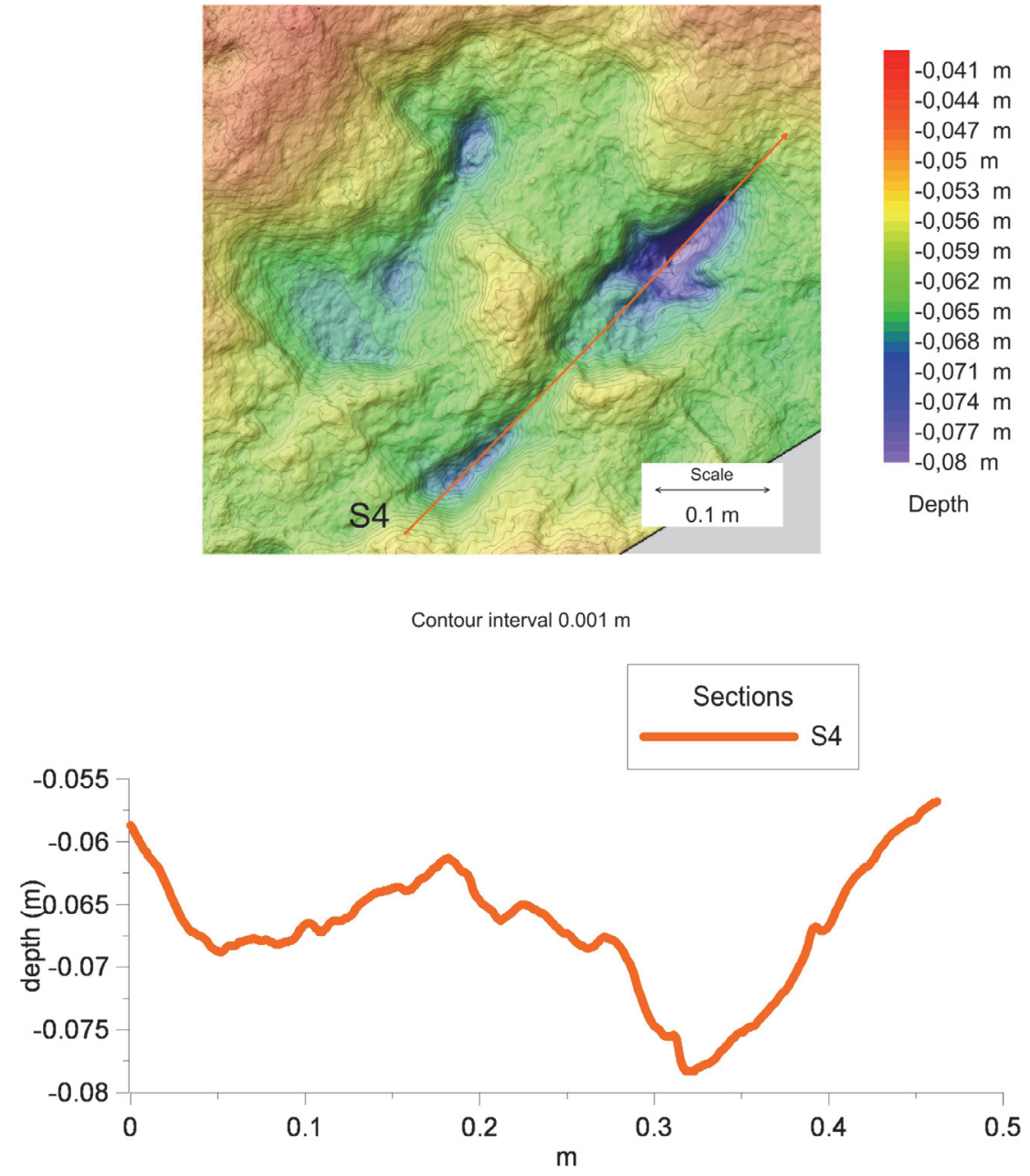

FIGURE 6. Shaded coloured 3D photogrammetric model of footprint F1 and F2 with relative section (S4) passing through the metatarsal impression and digit III.

indicates for this non-avian theropod trackmaker a limb kinematics in squatting position dramatically different from that adopted during the upright one. This raises questions on some relatively poorly explored aspects of dinosaur locomotion and behaviour. At the same time, the reconstruction of the complex movements made by the trackmaker suggests the occurrence of multiple interferences strongly influencing the final three-dimensional geometry of the tracks during the process of track formation.

\section{ACKNOWLEDGEMENTS}

We thank B. Tamiozzo and S. Panigutti for having brought to our attention the Riomartino tracks. We are grateful to T. Coppola, F. Battista, F. Di Fiore, G. Innamorati, and C. Zuccari for their help during field operations. We also warmly thank
Prof. M. Chiocchini for his assistance in the microfacies analysis and biostratigraphy. Various comments and suggestions by the editors (Daniel Hembree, Camille Grohe, Julien Louys), Jesper Milàn and an anonymous reviewer greatly improved the manuscript. This study was conducted within the 'PalaeoWorks' Project (www.facebook.com/pages/PalaeoWorks/ 1444856609165872).

\section{REFERENCES}

Accordi, G., Angelucci, A., and Sirna, G. 1967. Note illustrative della Carta Geologica d"Italia F. 159/160 Frosinone-Cassino. Servizio Geologico d'Italia, 1-77. Accordi, G., Carbone, F., Civitelli, G., Corda, L., De Rita, D., Esu, D., Funiciello, R., Kotsakis, T., Mariotti, G., and Sposato, A. 1988. Note illustrative della carta delle litofacies del Lazio-Abruzzo ed aree limitrofe. 
C.N.R.-P.F. Geodinamica: sottoprogetto 4. Quaderni della Ricerca Scientifica, 114:1-223.

Arnaud Vanneau, A. and Premoli Silva, I. 1995. Biostratigraphy and systematic description of benthic foraminifers from mid-Cretaceous shallow-water carbonate platform sediments at sites 878 and 879 (Mit and Takuyo-Daisan Guyots), p. 199-219. In Haggerty, J.A., Premoli Silva, I., Rack, F., and McNutt, M.K. (eds.), Proceedings of the Ocean Drilling Program, Scientific Results. College Station, Texas (Ocean Drilling Program), 144.

Avanzini, M. 1998. Anatomy of a footprint: bioturbation as a key to understanding dinosaur walk dynamics. Ichnos, 6:129-139.

Avanzini, M. 2000. Synaptichnium tracks with skin impression from the Anisian (middle Triassic) of the Southern Alps (val di non - Italy). Ichnos, 7:243-251.

Baird, D. 1980. A prosauropod dinosaur trackway from the Navajo Sandstone (Lower Jurassic) of Arizona, $p$. 219-230. In Jacobs, L.L. (ed.), Aspect of Vertebrate History: essay in honor of Harris Colbert. Flagstaff Museum of Northern Arizona Press, Flagstaff, Arizona.

Barnes, F.A. and Lockley, M.G. 1994. Trackway evidence for social sauropods from the Morrison Formation, Eastern Utah (USA). Gaia, 10:37-41.

Blob, R.W. 2001. Evolution of hindlimb posture in nonmammalian therapsids: biomechanical tests of paleontological hypotheses. Paleobiology, 27:14-38.

Carpenter, K. 1992. Behavior of hadrosaurs as interpreted from footprints in the "Mesaverde" Group (Campanian) of Colorado, Utah, and Wyoming. Contributions to Geology, 29:81-96.

Carrano, M.T. and Wilson, J.A. 2001. Taxon distributions and the tetrapod track record. Paleobiology, 27:564582.

Centamore, E., Di Manna, P., and Rossi, D. 2007. Kinematic evolution of the Volsci Range: a new overview. Italian Journal of Geosciences, 126:159-172.

Chiocchini, M. and Mancinelli, A. 1977. Microbiostratigrafia del mesozoico in facies di piattaforma carbonatica dei Monti Aurunci (Lazio meridionale). Studi Geologici Camerti, 3:109-152.

Chiocchini, M., Mancinelli, A., and Romano, A. 1984. Stratigraphic distribution of benthic foraminifera in the Aptian, Albian and Cenomanian carbonate sequences of the Aurunci and Ausoni mountains (Southern Latium, Italy). Benthos, 83:167-181.

Chiocchini, M., Farinacci, A., Mancinelli, A., Molinari, V., and Potetti, M. 1994. Biostratigrafia a foraminiferi, dasicladali e calpionelle delle successioni carbonatiche mesozoiche dell"Appennino centrale. Studi Geologici Camerti, Volume Speciale, 1994A:9-130.

Chiocchini, M., Pampaloni, M.L., and Pichezzi, R.M. 2012. Microfacies e microfossili delle successioni carbonatiche mesozoiche del Lazio e dell"Abruzzo (Italia centrale) - Cretacico. Memorie per servire alla descrizione della Carta Geologica d'Italia. ISPRA,
Servizio Geologico d'Italia, Dipartimento Difesa del Suolo, Rome.

Citton, P., Nicosia, U., and Sacchi, E. 2015. Updating and reinterpreting the dinosaur track record of Italy. Palaeogeography, Palaeoclimatology, Palaeoecology, dx.doi.org/10.1016/j.palaeo.2015.01.018.

Conti, M.A., Morsilli, M., Nicosia, U., Sacchi, E., Savino, V., Wagensommer, A., Di Maggio, L., and Gianolla, P. 2005. Jurassic dinosaur footprints from Southern Italy: footprints as indicators of constraints in paleogeographic interpretation. Palaios, 20:534-550.

Cosentino, D., Cipollari, P., Di Donato, V., Sgrosso, I., and Sgrosso, M. 2002. The Volsci Range in the kinematic evolution of the northern and southern Apennine orogenic system. Bollettino della Società Geologica Italiana, Special Issue, 1:209-218.

Cuesta, E., Díaz-Martinez, I., Ortega, F., and Sanz, J.L. 2015. Did all theropods have chicken-like feet? First evidence of a non-avian dinosaur podotheca. Cretaceous Research, doi:10.1016/j.cretres.2015.03.008.

Currie, P.J., Nadon, G.C., and Lockley, M.G. 1991. Dinosaur footprints with skin impressions from the Cretaceous of Alberta and Colorado. Canadian Journal of Earth Sciences, 28:102-115.

Currie, P.J. and Sarjeant, W.A.S. 1979. Lower Cretaceous dinosaur footprints from the Peace River Canyon, British Columbia, Canada. Palaeogeography, Palaeoclimatology, Palaeoecology, 28:103-115.

Farlow, J.O. 1992. Sauropod tracks and trackmakers: integrating the ichnological and skeletal records. Zubia, 10:89-138.

Fernandes, M.A., Fernandes, L.B.R., and Souto, P.R.F. 2004. Occurrence of urolites related to dinosaurs in the Lower Cretaceous of the Botucatu Formation, Paraná Basin, São Paulo State, Brazil. Revista Brasileira de Paleontologia, 7:263-268.

Gatesy, S.M., Middleton, K.M., Jenkins, F.A. Jr., and Shubin, N.H. 1999. Three-dimensional preservation of foot mouvements in Triassic theropod dinosaur. Nature, 399:141-144.

Gierlinski, G.D., Lockley, M.G., and Niedzwiedzki, G. 2009. A distinctive crouching theropod trace from the Lower Jurassic of Poland. Geological Quarterly, 53:471-476.

Kuban, G. 1989. Elongate dinosaur tracks, p. 57-79. In Gillette, D.D. and Lockley, M.G. (eds.), Dinosaur Tracks and Traces. Cambridge University Press, Cambridge.

Leonardi, G. 1987. Glossary and Manual of Tetrapod Footprint Palaeoichnology. Departamento Nacional da Produção Mineral, Brasilia, Brazil.

Lockley, M.G. 1991. Tracking dinosaurs: A new look at an ancient world. Cambridge University Press, Cambridge.

Lockley, M.G. 2009. New perspectives on morphological variation in tridactyl footprints: clues to widespread convergence in developmental dynamics. Geological Quarterly, 53:415-432. 
Lockley, M.G., Matsukawa, M., and Li, J. 2003. Crouching theropods in taxonomic jungles: ichnological and ichnotaxonomic investigations of footprints with metatarsal and ischial impressions. Ichnos, 10:169177.

Marty, D., Strasser, A., and Meyer, C.A. 2009. Formation and taphonomy of human footprints in microbial mats of present-day tidal-flat environments: implications for the study of fossil footprints. Ichnos, 16:127-142.

Milàn, J., Loope, D.B., and Bromley, R.G. 2008. Crouching theropod and Navahopus sauropodomorph tracks from the Early Jurassic Navajo Sandstone of USA. Acta Palaeontologica Polonica, 53:197-205.

Milàn, J., Avanzini, M., Clemmensen, L.B., GarciáRamos, J.C., and Piñuela, L. 2006. Theropod foot movement recorded by Late Triassic, Early Jurassic and Late Jurassic fossil footprints, p. 352-364. In Harris et al. (eds.), The Triassic-Jurassic Terrestrial Transition. New Mexico Museum of Natural History and Science Bulletin, Albuquerque.

Milner, A.R.C., Harris, J.D., Lockley, M.G., Kirkland, J.I., and Matthews N.A. 2009. Bird-like anatomy, posture, and behavior revealed by an Early Jurassic theropod dinosaur resting trace. PLoS ONE, 4:e4591.

Nicosia, U., Petti, F.M., Perugini, G., D’Orazi Porchetti, S., Sacchi, E., Conti, M.A., and Mariotti, N. 2007. Dinosaur Tracks as Paleogeographic Constraints: New Scenarios for the Cretaceous Geography of the Periadriatic Region. Ichnos, 14:69-90.

Parotto, M. and Praturlon, A. 1975. Geological summary of the Central Apennines. In Ogniben, L., Parotto, M. and Praturlon, A. (eds.), Structural Model of Italy. Quaderni de La Ricerca Scientifica, 90:257-311.

Petti, F.M., D'Orazi Porchetti, S., Conti, M.A., Nicosia, U., Perugini, G., and Sacchi, E. 2008. Theropod and sauropod footprints in the Early Cretaceous (Aptian) Apenninic Carbonate Platform (Esperia, Lazio, Central Italy): a further constraint on the palaeogeography of the Central-Mediterranean area. Studi Trentini di Scienze Naturali Acta Geologica, 83:113-124.

Platt, B.F. and Hasiotis, S.T. 2004. Newly discovered sauropod dinosaur tracks with skin and foot pad impressions from the Upper Jurassic Morrison Formation, Bighorn Basin, Wyoming, U.S.A. Palaios, 21:249-261.

Romano, M. and Citton, P. 2014. Reliability of digit length impression as ichnotaxonomical character: some consideration from Ichniotherium case study. Geological Journal. doi: 10.1002/gj.2601.

Romano, M., Citton, P., and Nicosia, U. 2015. Corroborating trackmaker identification through footprint functional analysis: the case study of Ichniotherium and Dimetropus. Lethaia, doi: 10.1111/let.12136.
Rossi, D., Bigi, S., Del Castello, M., and Di Manna, P. 2002. The structure of the Aurunci Mountains (southern Lazio): a balanced cross section and its restoration. Bollettino della Società Geologica Italiana, Volume Speciale, 1:151-159.

Sacchi, E., Cifelli, R., Citton, P., Nicosia, U., and Romano, M. 2014. Dimetropus osageorum n. isp. from the Early Permian of Oklahoma (USA): A trace and its trackmaker. Ichnos, 21(3): 175-192.

Sacchi, E., Conti, M.A., D'Orazi Porchetti, S., Logoluso, A., Nicosia, U., Perugini, G., and Petti, F.M., 2009. Aptian dinosaur footprints from the Apulian platform (Bisceglie, Southern Italy) in the framework of periadriatic ichnosites. Palaeogeography, Palaeoclimatology, Palaeoecology, 271:104-116.

Seitz, S.M., Curless, B., Diebel, J., Scharstein, D., and Szeliski, R. 2006. A comparison and evaluation of multi-view stereo reconstruction algorithms. Proceedings of the 2006 IEEE Computer Society Conference on Computer Vision and Pattern Recognition (CVPR"06) 0-7695-2597-0/06.

Souto, P.R.F. and Fernandes, M.A. 2015. Fossilized excreta associated to dinosaurs in Brazil. Journal of South American Earth Sciences, 57, 32-38.

Thulborn, R.A. 1990. Dinosaur Tracks. Chapman and Hall, London.

Turco, E., Schettino, A., Nicosia, U., Santantonio, M., Di Stefano, P., lannace, A., Cannata, D., Conti, M.A., Deiana, G., D'Orazi Porchetti, S., Felici, F., Liotta, D., Mariotti, N., Milia, A., Petti, F.M., Pierantoni, P.P., Sacchi, E., Sbrescia, V., Tommasetti, K., Valentini, M., Zamparelli, V., and Zarcone, G. 2007. Mesozoic paleogeography of the Central Mediterranean Region. Geoitalia 2007, VI Forum Italiano di Scienze della Terra, Epitome, 2:108.

Ullman, S. 1979. The interpretation of structure from motion. Proceedings of the Royal Society of London, B203:405-426.

Voigt, S., Berman, D., and Henrici, A.C. 2007. First wellestablished track-trackmaker association of paleozoic tetrapods based on Ichniotherium trackways and diadectid skeletons from the Lower Permian of Germany. Journal of Vertebrate Paleontology, 27:553570.

Wilson, J.A., Marsicano, C.A., and Smith, R.M.H. 2009. Dynamic Locomotor Capabilities Revealed by Early Dinosaur Trackmakers from Southern Africa. PLoS ONE, 4(10). doi:10.1371/journal.pone.0007331.

Zarcone, G., Petti, F.M., Cillari, A., Di Stefano, P., Guzzetta, D., and Nicosia, U. 2010. A possible bridge between Adria and Africa: new palaeobiogeographic and stratigraphic constraints on the Mesozoic palaeogeography of the Central Mediterranean area. Earth Science Reviews, 103:154-162. 


\section{APPENDICES}

APPENDIX 1. 3D interactive model of the track-bearing block (interactive version as zipped PDF along with STL file at palaeo-electronica.org/content/2015/1340-elongated-theropod-tracks).

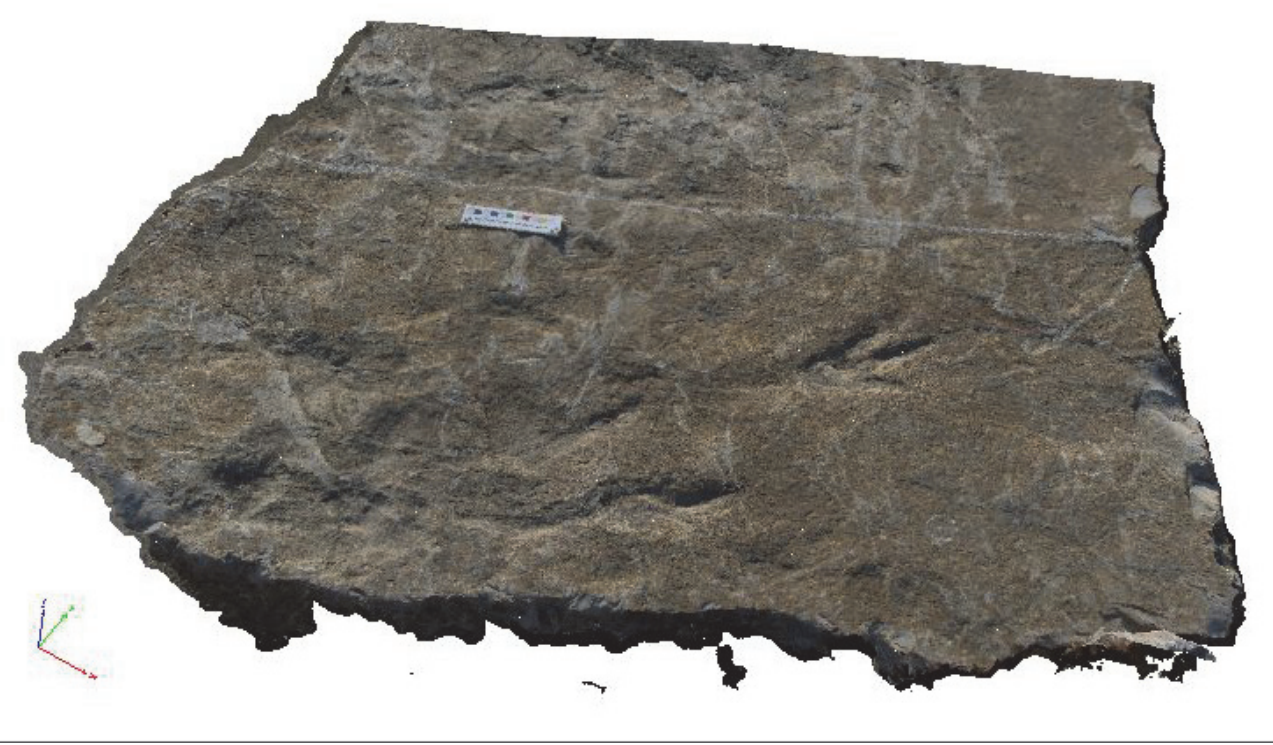

